\title{
EL ARTISTA BARROCO PEDRO RELLINS: REVISIÓN DE SU VIDA Y SU OBRA
}

\section{THE BAROQUE ARTIST PETER RELLINS: REVIEW OF HIS LIFE AND HIS WORK}

\author{
José Miguel SÁnchez Peña \\ Museo de Cádiz. España \\ hout.mg@hotmail.com \\ José Manuel Moreno Arana \\ morenoarana@gmail.com
}

Pedro Rellins (h. 1676-1728) fue un escultor y retablista, nacido en la actual Holanda, que desarrolló su actividad en Sanlúcar de Barrameda (Cádiz), ciudad a la que se trasladó siendo aún niño. En este artículo se hace un repaso por la historiografía que ha tratado al artista, se profundiza en los nuevos datos biográficos emanados de su expediente matrimonial y se aportan novedades sobre su obra.

Palabras clave: escultura, retablo, Barroco, siglo XVII, siglo XVIII, Sanlúcar de Barrameda.

Pedro Rellins (c. 1676-1728) was a sculptor and architect of altarpieces, born in the current Netherlands, who worked in Sanlucar de Barrameda (Cadiz), city to which moved still a child. In this article we review the historiography that has studied the artist, we delve into the new biographical details of your marriage certificate and we bring news about his work.

Keywords: sculpture, altarpiece, Baroque, 17th century, 18th century, Sanlúcar de Barrameda.

\section{PEDRO RELLINS EN LA HISTORIOGRAFÍA}

El origen extranjero de Pedro Rellins y la escasa documentación existente sobre su actividad artística, desarrollada principalmente en la ciudad de Sanlúcar de Barrameda entre finales del siglo XVII y los primeros decenios del XVIII, ha dificultado el estudio de su vida y su obra, aspectos que se nos presentan aún oscuros e incluso envueltos en errores. Y ello pese a que, como han destacado los diferentes autores que han tratado su figura, las primeras referencias que tenemos de él son casi contemporáneas y llamativamente elogiosas. Estamos hablando de 
las que hace Velázquez Gaztelu en 1758 en su libro Fundaciones de todas las Iglesias [...] de Sanlúcar de Barrameda, donde, además de informar de su autoría sobre los retablos mayores de las iglesias sanluqueñas de San Jorge y las Descalzas, alude a él como "hábil" o "famoso estatuario flamenco". . Aunque esta obra quedó inédita hasta fechas muy recientes, sus aportaciones fueron incorporadas por Guillamas y Galiano en 1854 en su Historia de Sanlúcar ${ }^{2}$.

Hubo que esperar un siglo para que, más allá de estas escuetas alusiones, se llevara a cabo la primera investigación sobre el escultor gracias a la iniciativa de un erudito local, Alejandro Zambrano, quien le dedica un artículo en $1956^{3}$. A él se debe casi todo lo que conocíamos sobre la biografía de Pedro Rellins: su supuesto nacimiento en 1667 en Venray (Holanda), su boda en Sanlúcar en 1696 y su muerte en ella en 1728. Igualmente, aportaba la afortunada identificación con el Pedro Sterling o Esterlin vecino de Sanlúcar que constaba como autor de las imágenes titulares de la cofradía de los Afligidos de Cádiz. Menos acertado estuvo en las atribuciones que hizo: el Nazareno de Rota, cuya relación con nuestro artista nos parece discutible, y el retablo mayor de la iglesia sanluqueña de la Trinidad, que resultó ser de 1679, anterior por tanto al establecimiento de Rellins en la ciudad, y obra del retablista Juan González de Herrera4

Zambrano contó para la realización de su artículo con la colaboración del investigador holandés Jan Verzijl. Curiosamente, tenemos noticia de que éste se adelantó varios años al sanluqueño en la publicación de la información obtenida en los archivos neerlandeses sobre los orígenes familiares del artista en la revista De Limburgse Leeuw $w^{5}$, la misma en la que posteriormente también el propio Zambrano volverá a insistir en el asunto a través de un nuevo artículo, esta vez en compañía de L. J. Morreau'

Estos precedentes bibliográficos en la tierra natal de Rellins justifican que otros autores de aquel país se hayan interesado en difundir su figura. Son los

${ }^{1}$ VELÁZQUEZ GAZTELU, Juan Pedro: Fundaciones de todas las Iglesias, Conventos y Ermitas de la M.N. y M.L. Ciudad de Sanlúcar de Barrameda, 1758. Reedición de la "Asociación Sanluqueña de Encuentros con la Historia y el Arte". Sanlúcar de Barrameda, 1995, pp. 90, 238 y 481.

${ }^{2}$ GUILLAMAS Y GALIANO, Fernando: Historia de Sanlúcar de Barrameda. Madrid, 1858, pp. 90 y 118 .

3 ZAMBRANO, Alejandro: "Un escultor flamenco del siglo XVII", Revista Albricias, Año IV, 1956, s/p.

${ }^{4}$ La autoría del retablo fue publicada en: HORMIGO SÁNCHEZ, Enrique: "El Retablista González de Herrera", El Periódico de la Bahía, 3 de noviembre de 1990, p. 13.

5 VERZIJL, Jan: "De Spaanse beeldhouwer Pedro Relins, een zoon van Venray", De Limburgse Leeuw, $\mathrm{n}^{\circ}$ 2, 1954, pp. 265-269.

${ }^{6}$ MORREAU, L. J. y ZAMBRANO, Alexander: "Een 17e eeuwse 'Vlaams' beeldhouwer", De Limburgse Leeuw, nº 8, 1960, pp. 106-111. 
casos de Bernard Kruysen ${ }^{7}$ y, ya en fechas más recientes, de M. P. J. van den Brand $^{8}$ y Rien van den Brand ${ }^{9}$. Todos vienen a reiterar lo dicho por Zambrano y sólo profundizan en el contexto histórico y familiar en el que suponen que nacería Pedro.

Ya en España, han sido múltiples las publicaciones que se han ocupado de él a lo largo de las últimas décadas. De este modo, desde el breve trabajo escrito en 1986 por uno de los autores de este presente artículo ${ }^{10}$, se han sucedido diferentes aportaciones, incluyendo hasta dos libros monográficos.

En 1999 Daza Palacios le documenta una nueva obra, el Cristo de la $\mathrm{Hu}-$ mildad y Paciencia de la hermandad de las Ánimas de la parroquia de la O de Sanlúcar. Pese a la importante novedad que supuso acrecentar la escasa producción segura del imaginero, el referido investigador identifica erróneamente la talla con otra del mismo título venerada en la Basílica de la Caridad ${ }^{11}$. Esta última se asigna ahora a Francisco de la Gándara y se fecha en 1605 tras las investigaciones del profesor Cruz Isidoro, a quien debemos asimismo la correcta identificación de la pieza realizada por Rellins con el Cristo de la Humildad y Paciencia que se conserva en la misma capilla de las Ánimas de la iglesia de la $\mathrm{O}^{12}$.

De 2001 es el primero de los libros que hemos señalado líneas atrás. Obra de Sánchez Alonso y Ruiz García, tiene como principal argumento la atribución del Nazareno de Rota a Rellins, teoría que, como hemos dicho, no compartimos. Se siguen las teorías de Zambrano para los aspectos biográficos, así como para el estudio de su producción, incluyendo equivocadamente dentro de esta al Cristo de la Humildad y Paciencia de la Basílica de la Caridad ${ }^{13}$.

Los últimos trabajos dedicados a nuestro escultor están firmados por los autores de estas líneas. Así, en 2002 salió a la luz otro libro, centrado ya exclusivamente

${ }^{7}$ KRUYSEN, Bernard: "Petrus Relingh, een beroemd Spaans beeldhouwer", Peel en Maas, 21 de noviembre de 1969.

${ }^{8}$ VAN DEN BRAND, M. P. J.: "Fragmenten uit het leven de Spaans beeldhouwer Pedro Relingh uit Venray (1667-1728)", Jaarboek van de Geschieden Oudheidkundige Kring Venray, $\mathrm{n}^{\circ} 16,1997$, pp. 1-18.

9 VAN DEN BRAND, Rien: "De Spaanse beeldhouwer Pedro Relingh uit Venray (1667-1728)", Venrays Verleden, ${ }^{\circ}$ II, 2005, pp. 26-38.

${ }^{10}$ SÁNCHEZ PEÑA, José Miguel: "Nuevas Aportaciones a la obra del escultor Peter Relingh", Anales de la Real Academia de Bellas Artes de Cádiz, n 4, 1986, pp. 49-53.

11 DAZA PALACIOS, Salvador: "La antigua cofradía de las Ánimas, Pedro Rellings y su Ecce-Homo", Sanlúcar de Barrameda, no 35, 1999, s/p.

${ }^{12}$ CRUZ ISIDORO, Fernando: "Francisco de la Gándara Hermosa de Acevedo, un escultor de principios del XVII", Laboratorio de Arte, $n^{\circ} 14,2001$, p. 37, nota 40. Del mismo autor, ver también: La Real Hermandad de las Angustias: estudio histórico y del patrimonio artístico. Sanlúcar de Bda., 2005, pp. 136-138.

13 SÁNCHEZ ALONSO, Gregorio y RUIZ GARCÍA, Juan Manuel. Rota y su Nazareno: la obra roteña de un escultor flamenco: Pedro Relins (1667-1728). Rota, 2001, pp. 89-114. 
en el artista. Junto con una profundización en los aspectos técnicos, se incorporan un buen número de piezas dentro de la nómina de atribuciones, como el Cristo y la antigua imagen mariana titulares de la cofradía de la Coronación de Jerez de la Frontera, el retablo mayor de la parroquia de Santo Domingo de Lepe o la imagen de Jesús del Consuelo de la parroquia del Carmen, el de la Humildad y Paciencia de la $\mathrm{O}$ o el Santo Domingo de Guzmán y el San Francisco del retablo mayor del convento de Madre de Dios, todas estas últimas en Sanlúcar. Respecto a las talla de los Afligidos de Cádiz, se profundiza en su autoría con documentación inédita ${ }^{14}$. Finalmente, hay que reseñar un sucinto artículo de 2009 en el que se daban a conocer nuevos datos biográficos que hoy tendremos la oportunidad de tratar con más detalle y ampliar ${ }^{15}$.

\section{APORTACIONES A SU BIOGRAFÍA}

Hemos dicho que Zambrano fue quien aportó los principales datos biográficos sobre Rellins. No obstante, el descubrimiento de su expediente matrimonial puede poner en duda la identificación que el referido investigador hizo con el "Petrus Relinghs" que figura en la partida de bautismo que dio a conocer y que incluso ha sido reproducida en los más recientes artículos de los van den Brand. Recordemos que estos autores sitúan su nacimiento en la ciudad holandesa de Venray en abril de 1667.

Hay que resaltar, en primer lugar, que la propia declaración del escultor incluida en dicho expediente, fechado en 1 de abril de 1696, reitera lo que ya sabíamos por su partida matrimonial, es decir, que era "natural de la ciudad de Bello obispado de Rusmunda en Flandes". Insistimos en ello pues parece lo más lógico identificar Bello con Venlo, localidad distinta a Venray, aunque muy próxima a ella y perteneciente también a la actual provincia holandesa de Limburgo y al antiguo Ducado de Güeldres, que estuvo bajo dominio español hasta el Tratado de Utrecht. En cuanto a los nuevos datos biográficos que incluye el documento, resulta llamativo que se informe de su llegada a Sanlúcar de Barrameda con 14 años, "sin haber hecho ausencia notable" de ella desde entonces ${ }^{16}$. Igualmente,

${ }^{14}$ SÁNCHEZ PEÑA, José Miguel. Peter Relingh, escultor y arquitecto de retablos. Cádiz, 2002.

${ }^{15}$ MORENO ARANA, José Manuel: "Nuevos datos biográficos sobre el imaginero Pedro Relingh". Diario de Cádiz, 7 de Mayo de 2009. Con anterioridad a estas aportaciones, en 2006 se escribió una sintética biografía que ha sido publicada en: MORENO ARANA, J. M.: "Relingh, Peter", Diccionario Biográfico Español, Vol. XLIII. Madrid, 2013, pp. 105-106.

16 Archivo General del Arzobispado de Sevilla (A.G.A.S.), fondo Arzobispal, sección Vicaría General, serie Matrimonios Ordinarios, legajo 2432, expediente $\mathrm{n}^{\circ} 130$. Ver apéndice documental. 
declara tener 20 años, lo que obligaría a localizar la fecha de su nacimiento hacia 1676, nueve años después de lo que se pensaba. Otro detalle interesante es que firma no como "Peter Relingh", sino como "Petro Rellins", cuestión también a tener en cuenta pues es la única rúbrica del artista que se ha encontrado hasta ahora (Figura 1$)^{17}$.

Rellins presenta además dos testigos, cuyas declaraciones son recogidas del mismo modo en este documento. Se trata de Cornelio Grencio y Maximiliano Coppens. El primero, que afirma ser "natural de Bello", contar con 49 años y trabajar como mercader en Sanlúcar, con domicilio en la calle Bolsa, aseguró que conocía a Pedro desde su nacimiento hasta la fecha, reiterando lo dicho por éste de su llegada a la ciudad española con 14 años. Lo mismo repite el segundo. Coppens era asimismo natural de Bello, mercader y vecino de la calle Bolsa y tenía 26 años ${ }^{18}$.

Aceptando todo lo anterior habría, por tanto, que concluir que es en torno a 1690 cuando Rellins se instala en Sanlúcar, siendo aún adolescente y viniendo seguramente acompañado por los mencionados mercaderes Grencio y Coppens. Algo que entra en contradicción con la pretendida estancia previa en Inglaterra que algunos autores, con Zambrano a la cabeza, plantearon para justificar, de manera un tanto forzada, el encargo al holandés del retablo de la iglesia de San Jorge por parte de la colonia inglesa asentada en Sanlúcar. Y, quizás lo más importante, estos nuevos datos obligan a pensar en un aprendizaje artístico que debió de desarrollarse, o como mucho completarse, en Sanlúcar o su entorno, como parecen testimoniar sus propias obras, inmersas en la estética de la escuela sevillana del momento.

Desgraciadamente, la escasez de la documentación, debido a la desaparición del archivo de protocolos notariales sanluqueño y de una parte importante del archivo parroquial, no nos permite profundizar mucho más sobre la vida de Rellins. Al margen de lo que acabamos de decir nada más sabemos de sus relaciones sociales y poco podemos suponer sobre el nivel económico del que gozó. Tenemos noticia de que tenía su casa en la calle Santo Domingo ${ }^{19}$ pero ni siquiera podemos asegurar que fuera propietario de ella. Hubiera sido para ello esencial la lectura de su testamento, si se hubiera conservado. Únicamente podemos aportar un dato incluido en el libro de Visitas de la Parroquia de la O del año 1714 en el que se paga a un "Pedro Rellins, maestro de cerero de esta Ciudad",

${ }^{17}$ Es por ello el apellido "Rellins" el que creemos más conveniente emplear a partir de ahora. Con él aludiremos al escultor en este artículo.

18 A.G.A.S., fondo Arzobispal, sección Vicaría General, serie Matrimonios Ordinarios, legajo 2432, expediente $\mathrm{n}^{\circ} 130$.

19 SÁNCHEZ PEÑA, J. M.: Peter Relingh..., op. cit., p. 18. 
7.070 reales en trece recibos, siendo el último del 14 de agosto de $1713^{20}$. En estas mismas cuentas se recoge otro trabajo, una reforma del retablo mayor de la misma iglesia, a un personaje homónimo, por lo que creemos que debe ser identificado con nuestro escultor. La circunstancia de que aparezca ejerciendo de cerero no es del todo extraña pues en la época era común que los diferentes artistas tuvieran que buscar otros medios alternativos fuera de su oficio con los que poder aumentar sus ingresos. En el caso del flamenco, pese a la fama que parece que tuvo, su producción documentada y aquella otra que se le puede atribuir son relativamente escasas, por lo que no creemos ilógica esta simultaneidad profesional ${ }^{21}$.

\section{ADICIONES A SU OBRA}

\section{LA HORNACINA PRINCIPAL DEL ANTIGUO RETABLO MAYOR DE LA PARROQUIA DE NUESTRA SEÑORA DE LA O DE SANLÚCAR DE BARRAMEDA (1713)}

Entre 1708 y 1710 Pedro Rellins talló para la cofradía de las Ánimas el referido Cristo de la Humildad y Paciencia de la parroquia de la O de Sanlúcar ${ }^{22}$. Pocos años después recibió el encargo de reformar el retablo mayor de la misma iglesia. Se trata de un trabajo inédito, aunque desgraciadamente no parece perdurar ningún resto del mismo. El escultor firmó recibo por esta obra el 19 de febrero de 1713. Consta además que se realizó por orden del visitador del arzobispado y consistió en hacer una nueva hornacina destinada a acoger la imagen mariana que presidía el referido retablo "para colocarla en el con mas desensia". Alcanzó un costo de 750 reales, de los cuales una parte, 470, fueron costeados por la fábrica parroquial y los 280 restantes fueron entregados por el colector Francisco Conte gracias a obvenciones procedentes de ciertos derechos parroquiales. Se afirma asimismo en la documentación que el estofado y dorado se hicieron de limosna y que se pagaron 14 reales a "dos hombres un dia para agrandar dicho nicho" ${ }^{23}$.

${ }^{20}$ Archivo Histórico Diocesano de Jerez de la Frontera (A.H.D.J.F.), Fondo Parroquial, Parroquia de Nuestra Señora de la O de Sanlúcar de Bda., Fábrica, Visitas, año 1714, p. 187.

${ }^{21}$ En la ciudad vecina de Jerez encontramos diversos ejemplos entre retablistas de la época: MORENO ARANA, J.M.: El Retablo en Jerez de la Frontera durante el siglo XVIII. Sevilla, 2014, pp. 95-97.

${ }^{22}$ DAZA PALACIOS, S.: "La antigua...,", op. cit., s/p.

${ }_{23}$ A.H.D.J.F., Fondo Parroquial, Parroquia de Nuestra Señora de la O de Sanlúcar de Bda., Fábrica, Visitas, año 1714, p. 219. Ver apéndice documental. 
Nada se sabe sobre sus características pues desapareció tras la construcción del retablo actual, de estilo rococó y fechado en $1767^{24}$, en el que se ha supuesto la intervención de Gonzalo Pomar y Jacome Vacaro ${ }^{25}$. En cualquier caso, la noticia tiene el valor de acrecentar su aún corta nómina de obras seguras y ofrecernos un nuevo testimonio de su faceta de retablista. Posiblemente su labor en esta pieza estaría todavía inmersa estilísticamente dentro de los últimos aleteos del retablo salomónico, sin que pueda descartarse del todo una incipiente evolución hacia la nueva tipología del estípite, soporte que ya había utilizado de una forma un tanto embrionaria más de diez años antes, en el retablo mayor del convento de las Descalzas de Sanlúcar, que estaba finalizado en 1705.

Respecto a la producción de retablos de nuestro artista, cabe recordar que a través de Velázquez Gaztelu se tiene constancia de su autoría tanto sobre el de las Descalzas como sobre el mayor de la capilla de San Jorge. Ambos se realizarían en los últimos años del seiscientos. Asimismo, presenta muy similares características el retablo mayor de la parroquia de Santo Domingo de Lepe, que procede del convento de dominicas de la misma localidad y que se le ha atribuido. Todos siguen unos modelos que recuerdan a la obra de uno de los principales representantes de la retablística sevillana de la época, Cristóbal de Guadix ${ }^{26}$. Lo vemos en el uso de columnas de fuste salomónico de tercio inferior cilíndrico o la organización de las calles laterales en dos registros escultóricos superpuestos. Otros detalles, como el remate de las hornacinas laterales del retablo de las descalzas sanluqueñas con combinación de frontones curvos rotos y rectos, están próximos a la obra documentada de Juan González de Herrera, artista afincado en Cádiz pero de procedencia hispalense, que realizó varios retablos para Sanlúcar. En este sentido, la formación artística de Rellins sigue siendo una incógnita sin resolver. Tan sólo se podría suponer contactos con otros retablistas y escultores de la época. Entre ellos, el que más posibilidades tuvo de conocer fue el sevillano Juan de Santa María Navarro, que hacia 1687, con 18 años, se instala en Sanlúcar, ciudad donde se casa en 1689 y nace su hijo primogénito, Matías José, en 169127. De hecho, el profesor Herrera García ha planteado la hipótesis de que existieran

${ }^{24}$ VELÁZQUEZ GAZTELU, J. P.: Fundaciones..., op. cit., p. 95.

25 ALONSO DE LA SIERRA FERNÁNDEZ, Lorenzo: "El retablo rococó en Cádiz y su entorno: evolución y creadores", Archivo hispalense, tomo 81, n 248, 1998, p. 248. MORENO ARANA, José Manuel: "La impronta genovesa en la escultura jerezana de la segunda mitad del siglo XVIII”, Revista de Historia de Jerez, n. ${ }^{\circ}$ 16-17, 2014, p. 189.

${ }^{26}$ La afinidad de los retablos sanluqueños de Rellins con la obra de Guadix ya ha sido señalada en: HALCÓN, Fátima: "El retablo salomónico", en El retablo sevillano. Sevilla, 2009, pp. 287-288.

27 MORENO ARANA, J.M.: El Retablo..., op. cit., p. 337. 
contactos entre los Navarro y Rellins debido a las afinidades que ofrecen ciertos detalles de sus retablos 28 .

\section{ATRIBUCIONES}

\section{CRISTO DE LA HUMILDAD Y PACIENCIA DEL SANTUARIO DE NUESTRA SEÑORA DE REGLA DE CHIPIONA}

Es una imagen sedente del Redentor en actitud pensativa que recibe culto en un sencillo altar de estilo neogótico de maderas pintadas, en la cabecera de la nave de la epístola del Santuario de Nuestra Señora de Regla de Chipiona ${ }^{29}$.

Supuestamente, se representa a Cristo en actitud de meditación tras el suplicio de la Flagelación. La imagen se halla sentada en un pódium que es el de origen, pues forma parte de la escultura según el estudio técnico realizado "in situ".

Estudiada la imagen y dadas sus características técnicas y artísticas, puede atribuirse al escultor flamenco. Estimamos que es obra de madurez del artista, pues supera notablemente al homónimo de la Parroquia de la O de Sanlúcar; no es de extrañar que la imagen sanluqueña tuviese gran aceptación y le llegasen al escultor encargos similares, lo que llamamos "réplicas", algo frecuente en la producción de los artistas cuando se acierta con un modelo o tema concreto.

Hasta el momento presente y de lo que conocemos, es la obra más acabada y correcta del escultor, con un estudio anatómico seguramente desarrollado a partir de un modelo (del natural). La cabeza del Señor se apoya en su mano derecha y el rostro expresa dulzura, tristeza y abandono. El cabello aparece muy bien compuesto a ambos lados de la cabeza y sobre la espalda; destacamos el perfil izquierdo con la compleja composición del cabello. Está tallado formando mechones largos y suaves, sin entrar en detalles minuciosos, de forma similar al Cristo del Consuelo de Sanlúcar. Siendo una imagen que permanece siempre en su altar, dentro de una hornacina, es difícil contemplarla en todo su conjunto e imaginar la calidad de la misma, sólo apreciable fuera de su emplazamiento habitual. Sin embargo, pone la nota negativa, tan perjudicial para esta obra, el repinte generalizado que cubre toda la imagen, que la desvirtúa considerablemente (Figuras 2-4).

${ }^{28}$ HERRERA GARCÍA, F. J.: "La familia Navarro y la expansión del retablo de estípites en Andalucía Occidental", en Nuevas Perspectivas críticas sobre historia de la escultura sevillana. Sevilla, 2007, p. 53.

${ }_{29}$ Agradecemos al Rdo. P. Guardián del Santuario, Fray José Ricardo Gallardo todas las facilidades otorgadas para el estudio de esta imagen (mayo de 2015). Está realizada en madera de cedro y los ojos van pintados sobre la talla. Mide $110 \mathrm{cms}$. de altura. 


\section{VIRGEN CON EL NIÑO DEL CORO BAJO DEL CONVENTO DE MADRE DE DIOS DE SANLÚCAR DE BARRAMEDA (PROCEDENTE DE LA CAPILLA DE SAN JORGE)}

Esta imagen de la Virgen con el Niño presidió el retablo mayor de la capilla de San Jorge. Como bien sabemos, durante muchos años y en pleno siglo XX San Jorge se mantuvo cerrada al culto. Una vez restaurada, se hizo cargo de ella la Hermandad del Rocío, que es quien la reabre y coloca a su titular presidiendo el retablo. Fue entonces depositada la antigua talla mariana en el convento de Madre de Dios, donde se expone en el coro bajo de la clausura ${ }^{30}$.

Algunos historiadores la creen obra napolitana ${ }^{31}$ pero examinada la imagen, la estimamos como una obra indudable del artista flamenco. Pero hemos de aclarar que se colocaría en el camarín central del retablo de San Jorge muy posteriormente a la ejecución del mismo, pues la imagen queda muy distante estilísticamente de las esculturas del retablo, que delatan un arcaísmo notable.

Es una talla completa, realizada en madera de pino, que luce amplios ropajes con elegantes plegados, en un valiente contraposto ${ }^{32}$. Presenta rica policromía con estofados y corladuras por el reverso de los pliegues. Tiene ojos de cristal y pestañas postizas. Pensamos que la encarnadura del rostro no es la de origen, pues se aprecia que está repintada en su totalidad. Como detalle curioso la Virgen calza zapatos que asoman bajo la túnica. Su rostro está perfectamente relacionado con las dos Dolorosas atribuidas a Rellins: la de Cádiz y la de Villaluenga. La cabellera, de elegante y sobre todo original composición, aparece dispuesta hacia atrás, de corte helenístico, y recogida en un moño de complejos bucles que cae por la espalda, recordándonos a conocidas Venus o doncellas romanas. Queda evidente en estos detalles curiosos, en los que el artista se recrea en su obra, su vocación clásica. Estos detalles, ya de por sí insólitos, originalísimos e infrecuentes, hacen que el escultor realice la imagen sin toca o velo que le cubra la cabeza, que sería lo normal en este caso (Figuras 5-7).

Respecto a la imagen del Niño que sostiene en su mano izquierda, y que no forma parte del conjunto, también ofrece un dinamismo palpable en la posición de brazos y piernas, y movimiento general de la imagen. Ofrece una bella policromía clara y transparente, simulando tonos rubios. La tipología de su rostro y el tratamiento del cabello tienen sus precedentes en dos cabezas de ángeles alados

${ }^{30}$ Hemos de agradecer a la Comunidad de Madres Dominicas las facilidades otorgadas para el estudio de la imagen.

${ }^{31}$ LOBATO O.P., Fr. Abelardo y TORIBIO GARCÍA, Manuel: El Monasterio de Madre de Dios. Sanlúcar de Bda., 1995, p. 99. GÓMEZ DÍAZ, Ana María: Guía Histórico Artística de Sanlúcar. Sanlúcar de Bda., 1993, p. 163.

${ }^{32}$ La terminación del manto sobre su brazo izquierdo presenta una mutilación. Es posible, pues ocurre con frecuencia, que se hiciera ex profeso para vestir la imagen con telas naturales. 
de los retablos de San Jorge y de las Descalzas. El primero se halla en una tarja situada a gran altura sobre un medallón con el Espíritu Santo, centrado en el frontón curvo partido bajo el grupo del San Jorge. El de las Descalzas se encuentra en otra tarja, bajo el altorrelieve de la Transverberación de Santa Teresa.

\section{VIRGEN DEL CARMEN DE LA PARROQUIA DEL CARMEN DE SANLÚCAR DE BARRAMEDA}

Es una imagen de tamaño natural que preside el camarín central del retablo mayor de la actual parroquia del Carmen de Sanlúcar de Barrameda, antiguo convento carmelita descalzo. En la mayoría de las ocasiones se halla vestida con ricas telas recamadas o bordadas, y sostiene al Niño en su brazo izquierdo. El rostro de la Virgen, con la boca cerrada y la mirada distante, es de expresión grave y serena, de gran belleza, con ojos de cristal y pestañas postizas, y posee todos los rasgos característicos de Rellins.

Aunque la imagen aparece vestida, es de talla estofada por la parte frontal; el dorso se halla pintado de un tono neutro sin policromar. La estructura o aspecto que presenta es un hábito talar con cíngulo a la cintura, siendo los brazos tallados y fijos ${ }^{33}$. El cuerpo se apoya en su pierna izquierda, basculando el conjunto y dejando ver los volúmenes correspondientes a la pierna derecha. Al no llevar manto ni el escapulario tan característico en esta advocación, nos plantea ciertas dudas, que en cierta forma podrían aclararse con un estudio a fondo de la imagen ${ }^{34}$. La túnica o hábito presenta un estofado sobre fondo color tierra o siena tostada oscura. Las encarnaduras del rostro y manos parecen originales, ricas en matices y transparentes, de gran corrección. Lleva sobre la cabeza peluca de pelo natural, pues el escultor concibió el cráneo liso con esta finalidad ${ }^{35}$.

Respecto a la imagen del Niño, podemos hacer comentarios similares al de la imagen de Madre de Dios; lo sostiene en su mano izquierda. No obstante, es éste de mayor tamaño y participa de todas las características barrocas del anterior. Tiene ojos de cristal, igual que la Virgen, en tonos claros y llama la atención la actitud gesticulante de los brazos, que contrasta con la serenidad de la Madre (Figura 8).

${ }^{33}$ La imagen aparece vestida normalmente; los comentarios que hacemos sobre la imagen sin vestir son a través de fotografías existentes.

${ }^{34}$ Ha sido estudiada desde el presbiterio del templo y a través de fotografías.

${ }^{35}$ Un examen visual fuera del camarín, con detenimiento, y por supuesto un examen radiográfico nos permitirían sacar importantes conclusiones. Hemos de agradecer a Juan Antonio Sánchez Pacheco la información de sumo interés acerca de las imágenes de la Virgen del Carmen y de Santa Teresa. 


\section{SANTA TERESA DE JESÚS DE LA PARROQUIA DEL CARMEN DE SANLÚCAR DE BARRAMEDA}

Es una imagen de candelero para vestir y de tamaño natural, que se halla ocupando el retablo colateral de la epístola de la parroquia del Carmen de Sanlúcar ${ }^{36}$. Aparece revestida con ricas telas recamadas y bonete, como Doctora de la Iglesia. La Santa eleva la mirada hacia el Ángel, con la boca entreabierta y los brazos abiertos, gesticulantes.

Tanto la policromía del rostro y manos, de tonos suaves, parecen originales y se hallan en buen estado de conservación. Su cabeza está concebida con cráneo liso para llevar peluca de pelo natural, al igual que la Virgen del Carmen y la Dolorosa de San Lorenzo de Cádiz, con la que comparte un gran parecido físico. Posee ojos de cristal y pestañas postizas. Es una talla resuelta mediante un candelero troncocónico (como la mayoría de las Dolorosas), con base elíptica, aún de origen afortunadamente, con busto tipo "jaula", de donde arrancan los brazos, que son fijos en los hombros y articulados en los codos.

La figura del Ángel, al que dirige la mirada la Santa, comparte los rasgos estilísticos de Rellins, siendo el rostro muy similar al Niño de la Virgen del Carmen.

Sus rasgos faciales no dejan lugar a dudas en cuanto a la mano del escultor flamenco; es posiblemente una de sus obras del período final (Figuras 9 y 10).

\section{ANOTACIONES SOBRE OTRAS OBRAS}

\section{VIRGEN DE LOS DOLORES DE LA PARROQUIA DE VILLALUENGA DEL ROSARIO (ANTIGUA VIRGEN DE LA AFLICCIÓN DE LA COFRADÍA DE LA CORONACIÓN DE JEREZ DE LA FRA.)}

Esta imagen de la Dolorosa formó parte de la hermandad jerezana de la Coronación de Espinas, debiendo de ser realizada hacia 1715-1725. El 4 de mayo de 1935, un incendio fortuito provocó daños de consideración, por lo que la talla fue trasladada a Sevilla al estudio del escultor Agustín Sánchez Cid y restaurada posteriormente, siendo bendecida de nuevo tras la intervención y repuesta al culto. No obstante, por motivos que ignoramos, en 1950 la hermandad sustituye esta antigua Dolorosa por una nueva imagen, obra del escultor sevillano José Rivera García, que recibe culto desde esas fechas hasta la actualidad ${ }^{37}$.

\footnotetext{
${ }^{36}$ Con motivo de los fastos que se llevan a cabo en conmemoración del V Centenario del nacimiento de la Santa se halla ubicada la imagen, temporalmente, en un pequeño retablo en la nave de la epístola, junto al crucero. En la actualidad el ángel que le acompaña se encuentra retirado del culto.

${ }^{37}$ ROSA MATEOS, Antonio de la: Imaginería Procesional en la Semana Santa de Jerez. Jerez de la Frontera. 2012, pp. 103-104.
} 
Tras su desaparición, y a través de antiguas fotografías, se propuso su atribución a Rellins, en base a sus caracteres estilísticos y morfológicos, y sobre todo por sus analogías a otras tallas femeninas del artista flamenco ${ }^{38}$. Con el paso de los años y en fechas recientes se descubre e identifica esta Dolorosa (estudiada a través de fotografías) con la que recibe culto en Villaluenga del Rosario (Cádiz), en la iglesia parroquial de San Miguel ${ }^{39}$.

Es una imagen de tamaño natural, y sus rasgos faciales la ponen en relación con diversas tallas, todas ellas muy características y personales de Rellins, que representan a una mujer en edad madura, algo frecuente en la producción del artista; ponemos como ejemplo la Dolorosa de los Desconsuelos, titular de la Cofradía de los Afligidos de Cádiz, que tiene rasgos muy afines pero la cabeza gira a la derecha y lleva las manos entrelazadas. La expresión del rostro con rictus de dolor, el giro de la cabeza, sus facciones, los pómulos, el dibujo de las cejas, la morfología de sus labios y de la nariz, completan una serie de detalles que son grafismos propios del escultor flamenco.

\section{CRISTO DE LA HUMILDAD Y PACIENCIA DE LA PARROQUIA DE LA O DE SANLÚCAR DE BARRAMEDA (1708-1710) ${ }^{40}$}

Dadas sus características y rasgos estilísticos, esta anónima talla fue puesta en relación con la obra de Pedro Rellins ${ }^{41}$, confirmándose posteriormente su autoría de forma documental ${ }^{42}$, aunque confundida con la homónima del Santuario de la Caridad, como ya dijimos. Durante muchos años hemos podido comprobar que presentaba un aspecto de total abandono, con un grado de deterioro alto y en general con un estado de conservación muy precario, siendo restaurada la misma en el año $2009^{43}$. Con tal motivo se editó un díptico con algunos datos históricos y técnicos sobre esta imagen de Cristo ${ }^{44}$. En el mismo la talla es nombrada como "Santísimo Cristo de la Luz", lo que vuelve a repetir un error en el que ya cayera en su día Daza Palacios. Merece la pena, por ello, dedicar unas pocas líneas al asunto para intentar aclararlo.

\footnotetext{
38 SÁNCHEZ PEÑA, J. M.: Peter Relingh..., op. cit., pp. 23-24.

${ }^{39}$ ROSA MATEOS, A. de la: Imaginería..., op. cit., pp. 103-104.

${ }^{40}$ Hemos de agradecer al Rdo. P. D. Luis Núñez Rodríguez las facilidades otorgadas para el estudio de la imagen en 1992.

${ }^{41}$ SÁNCHEZ PEÑA, J. M.: Peter Relingh..., op. cit., pp. 25-27.

42 DAZA PALACIOS, S.: "La antigua...", op. cit., s/p.

${ }^{43}$ La restauración fue sufragada por la Fundación Barrero Pérez y realizada por María José Gómez Santiago.

${ }^{44}$ Se titula Santísimo Cristo de la Luz. Parroquia Mayor Ntra. Sra. de la O. Sanlúcar de Barrameda. Noviembre 2009. Está editado por la Fundación Barrero Pérez y firmado por la restauradora.
} 
Partimos de la base de la realización de la imagen, según Daza Palacios, entre 1708 y 1710. Las cuentas de la cofradía de Ánimas llaman a la talla "EcceHomo", y aclaran su destino dentro de la capilla de la hermandad, el altar mayor. A través de la consulta de un libro de visitas pastorales conservado en el Archivo General del Arzobispado de Sevilla y correspondiente al año 1715, queda claro también la reciente ejecución de la imagen a la que se alude como "Ecce Homo de madera barnisada"45. La siguiente referencia nos la aporta Velázquez Gaztelu al hablar de esta capilla, siendo la primera vez en la que se habla de ella con el título de "Humildad y Paciencia": "hoy sirve de altar mayor un lienzo grande [...] delante del cual sobresale en forma de retablo un donoso tabernáculo, apoyado sobre un compartimento de gradas para luces con tres nichos inferiores: en el medio está una pequeña imagen de Nuestra Señora del Sufragio y en el tabernáculo superior una devota y perfectísima imagen de nuestro Señor Jesucristo, en el ternísimo paso de su humildad y paciencia, de elegante mano que ignoramos". En este sentido, no deja de sorprender su desconocimiento de su autoría, habiendo sido este historiador una de las principales fuentes para el conocimiento de la figura de Rellins. Sea como sea, lo que Velázquez Gaztelu añade a continuación empieza ya a volver todo más confuso. Por un lado, nos dice que fue solemnemente trasladada al lugar que ocupa en torno a 1717, algo que tiene sentido por la cercanía con la fecha de su realización. Sin embargo, y en contradicción con lo anterior, por lo que hay que suponerlo un lapsus, asegura que esta talla formó parte de una cofradía de negros desaparecida setenta años antes, que la sacaba en procesión junto a un "Señor de la Columna" y al aludido "Cristo de la Luz". A este último lo sitúa "en particular altar a la entrada la misma capilla"46.

Suponemos que esto ha sido precisamente lo que ha motivado que la obra de Rellins sea identificada erróneamente con ese "Cristo de la Luz", ya que se venera en la actualidad en un pequeño retablo situado en primer lugar a la derecha desde la entrada. No obstante, es un altar de cronología posterior, de corte neoclásico, al que la imagen de la Humildad y Paciencia se trasladaría seguramente a lo largo del siglo XIX tras la construcción en la misma época del retablo mayor que actualmente preside esta estancia ${ }^{47}$. Hasta hace pocos años se veneraba en ese nuevo altar mayor decimonónico de la capilla un crucificado que creemos que debe de ser en realidad el reiterado "Cristo de la Luz". Aunque resulte contradictorio, así lo parece indicar la propia documentación presentada por Daza

${ }^{45}$ A.G.A.S., fondo Arzobispal, sección Gobierno, serie Libros de Visitas Pastorales, legajo 5187, f. 553.

46 VELÁZQUEZ GAZTELU, J. P.: Fundaciones..., op. cit., p. 90.

${ }^{47}$ Nos parece totalmente desacertada la identificación que hace Daza Palacios de este retablo neoclásico con el que hace para la imagen del Cristo de la Luz Andrés Marín en la década de los setenta del siglo XVIII, ya que debió de ser aún una pieza de estilo rococó (DAZA PALACIOS, S.: "La antigua...", op. cit., s/p.). 
Palacios, que habla de un crucificado en el altar de esta advocación en $1769^{48}$. En definitiva, sería en la reforma neoclásica, que afectó a toda la capilla, cuando, por tanto, se intercambió la posición de ambas esculturas dentro de la misma, dando lugar de este modo a la reciente confusión entre ambas ${ }^{49}$.

\section{APÉNDICE DOCUMENTAL}

\section{Documento $\mathbf{n}^{\mathbf{0}} \mathbf{1}$}

\section{Expediente matrimonial de Pedro Rellins (1696).}

A.G.A.S., expedientes matrimoniales, legajo 2432, expediente $\mathrm{n}^{\mathrm{o}} 130$.

"Pedimento / En la ciudad de Sanlucar de Barrameda en primero de Abril de mil y seiscientos y noventa y seis años, ante su merced Lizenciado Don Antonio Gadea Vicario de esta ciudad por ante el presente notario Pedro Relins vecino de ella dixo que siendo Dios nuestro señor servido quiere contraer matrimonio en faz de nuestra santa Madre Iglesia con Ysabel Maria de Melo natural y vecina de esta ciudad i para que conste de su libertad, pidio se le reciva su declaracion e informacion que ofreze Justicia etc.

Auto / Y visto por su merced dicho señor Vicario, mando se reciva la declaracion al contrayente $i$ la ynformacion ofrecida y lo cometio el presente notario y assi lo probeyo i lo firmo. $=$

Gadea (rubricado) / Geronimo Logerot y Soto escribano (rubricado)

Declaracion / En la dicha ciudad de Sanlucar de Barrameda en el dicho dia yo el notario rezevi Juramento segun forma de derecho del contrayente i so cargo de el prometio decir verdad, i preguntado = dixo que se llama Pedro Relins i que es hijo de Simon Relins y de Maria Vogelsan natural de la ciudad de Bello obispado de Rusmunda en Flandes, donde vivio hasta hedad de catorce años, $i$ de dicha hedad vino a esta ciudad, donde ha vivido hasta oy sin aver hecho ausencia notable de una y otra parte, y que no es ni ha sido casado, no ha hecho voto de castidad, ni de religion, ni ha dado palabra de casamiento a muger alguna, ni tiene otro impedimento para el matrimonio que quiere contraer con Ysabel Maria de Melo, de quien no es pariente

48 DAZA PALACIOS, S.: "La antigua...", op. cit., s/p. En concreto, se recoge que el crucificado procedía del remate del antiguo retablo mayor de la parroquia y fue desmontado con motivo de la construcción del nuevo, que fue costeado por María Ashley. Tras ser retocado por el pintor Francisco Alanís se colocó en el altar del Cristo de la Luz llevándose esta señora el crucifijo que existía en dicho altar a su casa. Es decir, hay que suponer que existió un primitivo cristo de este título y de éste tomaría su nombre el que lo sustituyó.

49 Decimos confusión reciente porque hasta hace unas décadas a la obra de Rellins se le seguía conociendo como "Cristo de la Humildad y Paciencia" (SÁNCHEZ GUERRERO, Manuel Felipe: "Breve aproximación a la iglesia mayor parroquial de Nuestra Señora de la O”, Sanlúcar de Barrameda, n² 23, 1987, s/p.). 
en grado alguno; y que todo lo lleva dicho es la verdad so cargo del Juramento fecho $i$ lo firmo; y que es de hedad de veinte años. $=$

Petro Rellins (rubricado) / Geronimo Logerot y Soto escribano (rubricado)

Testigo / En la dicha ciudad de Sanlucar en el dicho dia para la dicha ynformacion el contrayente presento por testigo a Cornelio Grencio que assi dixo nombrarse y ser mercadel natural de Bello en Flandes y vezino desta calle de la Bolsa; del qual recevi Juramento segun forma de derecho y so cargo de el prometio decir verdad, y preguntado = Dixo que conoce al dicho Pedro Relins desde que nacio, asi en la ciudad de Belo en Flandes donde vivio hasta hedad de catorce años, como en esta ciudad, donde ha vivido el tiempo restante hasta oy, sin que de una y otra parte aya hecho ausencia notable, y lo ha tratado y comunicado y sabe que no es ni ha sido casado, ni tiene noticia aya palabra de casamiento a muger alguna, ni que tenga otro algun impedimento para el matrimonio que quiere contraer con Ysabel Maria de Melo, de quien sabe no es pariente en grado alguno y que todo lo que lleva dicho es la verdad so cargo del Juramento fecho y lo firmo; y que es de hedad de quarenta y nueve años. $=$

Cornelio Grencio (rubricado) / Geronimo Logerot y Soto escribano (rubricado)

Testigo / En la dicha ciudad de Sanlucar de Barrameda en el dicho dia para la dicha ynformacion el dicho contrayente presento por testigo a Maximiliano Copens, que assi dixo nombrarse, i ser mercader natural de la ciudad de Bello en Flandes $i$ vecino desta ciudad en la calle de la Bolsa, del qual rezevi Juramento segun forma de derecho i so cargo de el prometio decir verdad, i preguntado = Dixo que conoce al dicho Pedro Relins desde que nacio, asi en la dicha ciudad de Bello en Flandes, donde vivio hasta hedad de catorze años, y en esta ciudad el tiempo restante hasta oy, i siempre lo ha tratado i comunicado, sin que de una y otra parte aya hecho ausencia notable, $i$ sabe que no es ni ha sido casado, ni tiene noticia aya hecho voto de castidad, ni de religion, ni que aya dado palabra de casamiento a muger alguna, ni que tenga otro algun impedimento para el matrimonio que quiere contraer con Ysabel Maria de Melo, de quien sabe no es pariente y que lo que lleba dicho es la verdad so cargo del Juramento fecho y lo firmo y que es de hedad de veinte y seis años. =

Maximiliano Coppens (rubricado) / Geronimo Logerot y Soto escribano (rubricado)

Auto / En la dicha ciudad de Sanlucar de Barrameda en el dicho dia primero de Abril de mil y seiscientos y noventa i seis años su merced Lizenciado Don Antonio Gadea Vicario desta ciudad aviendo visto estos autos $=$ Dixo que originales se remitan a manos del Señor Juez y Vicario general deste Arzobispado para que en su vista prober lo que fuere Justicia y assi lo probeyo, mando, i firmo. $=$

Don Antonio Gadea (rubricado) / Geronimo Logerot y Soto escribano (rubricado)

En 6 de Abril de 1696

Lizencia y se le dispensan las amonestaciones de su tierra." 


\begin{abstract}
Documento $\mathrm{n}^{\circ} 2$
Realización de la hornacina principal del antiguo retablo mayor de la Parroquia de Nuestra Señora de la $O$ de Sanlúcar de Bda. por Pedro Rellins (1713).

A.H.D.J.F., Fondo Parroquial, Parroquia de Nuestra Señora de la O de Sanlúcar de Barrameda, Fábrica, Visitas, año 1714, p. 219.

"Ittem con intervension del vicario de esta Ciudad y de orden que a boca declaró averle dado el Señor Visitador de que su Merced hace memoria se hizo nicho nuevo en el Altar maior adonde estaba nuestra señora para colocarla en el con mas desensia para lo qual contribuio esta fabrica con quatrozientos y setenta reales para madera y Escultor que todo ymporto setezientos y cinquenta reales de los quales los 470 referidos dio esta fabrica como quedo dicho y los 280 restantes declara el mayordomo haver persevido de Don Francisco Conte collector de obensiones los mismos que declaro el dicho estaban en su poder del tiempo de la vacante de Don Pedro Millan sachristan maior que de fue de esta iglesia de los derechos parrochiales que tocaron y es advertencia que lo demás del gasto en estofarlo y dorarlo se dio de limosna, y de los dichos quatrozientos y setenta reales dio Recivo Pedro Rellins en 19 de febrero de 1713 que se vio, rubrico y avonan - 470

Del jornal de dos hombres un dia para agrandar dicho nicho catorze reales - 14."
\end{abstract}

Fecha de recepción: 8 de septiembre de 2015.

Fecha de aceptación: 20 de noviembre de 2015. 


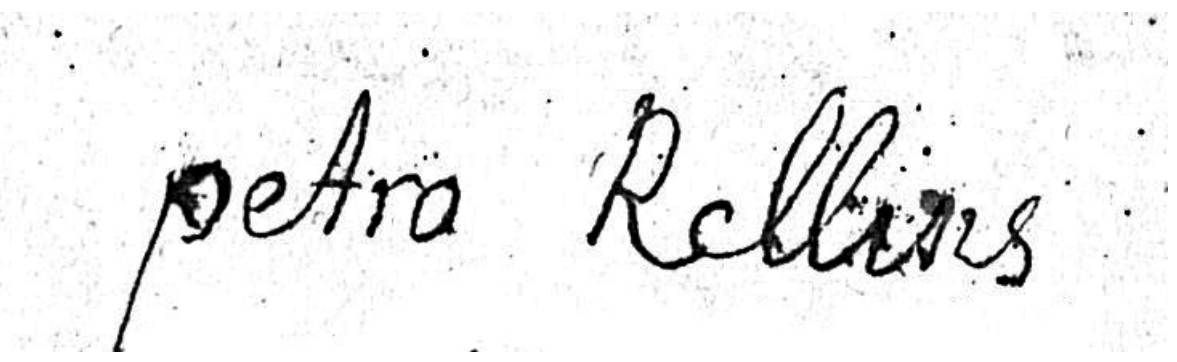

Figura 1. Firma de Pedro Rellins contenida en su expediente matrimonial (1696).

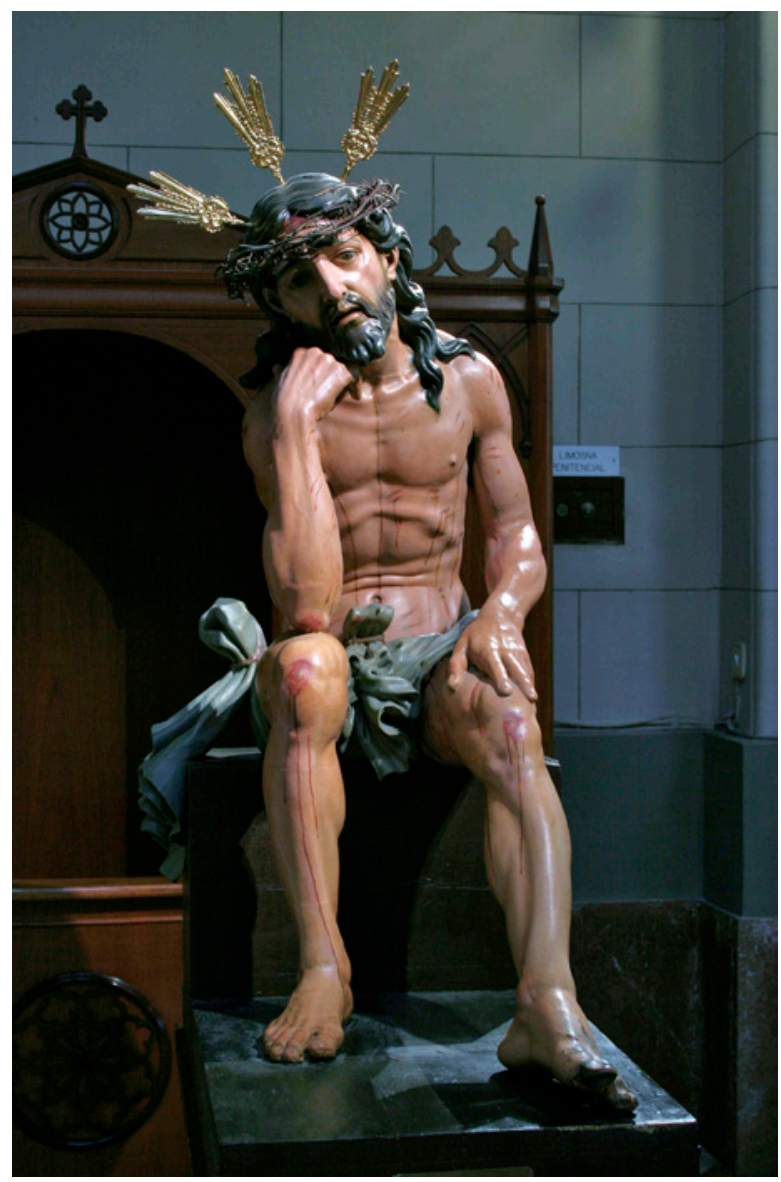

Figura 2. Cristo de la Humildad y Paciencia. Santuario de Nuestra Señora de Regla de Chipiona. 


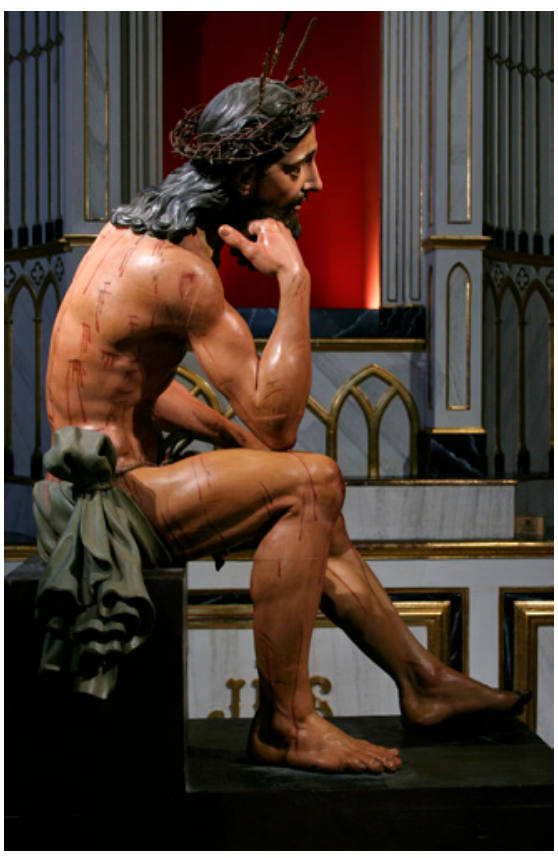

Figura 3. Cristo de la Humildad y Paciencia. Santuario de Nuestra Señora de Regla de Chipiona (detalle).

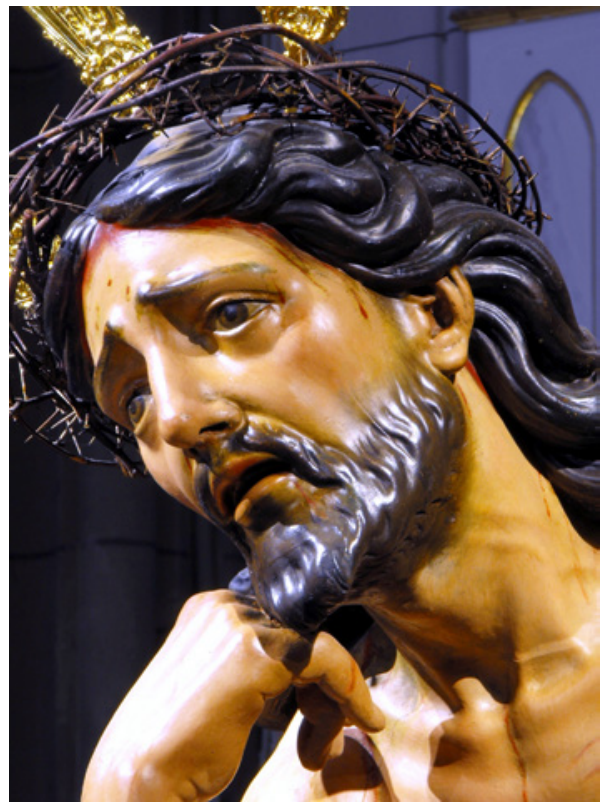

Figura 4. Cristo de la Humildad y Paciencia. Santuario de Nuestra Señora de Regla de Chipiona (detalle). 


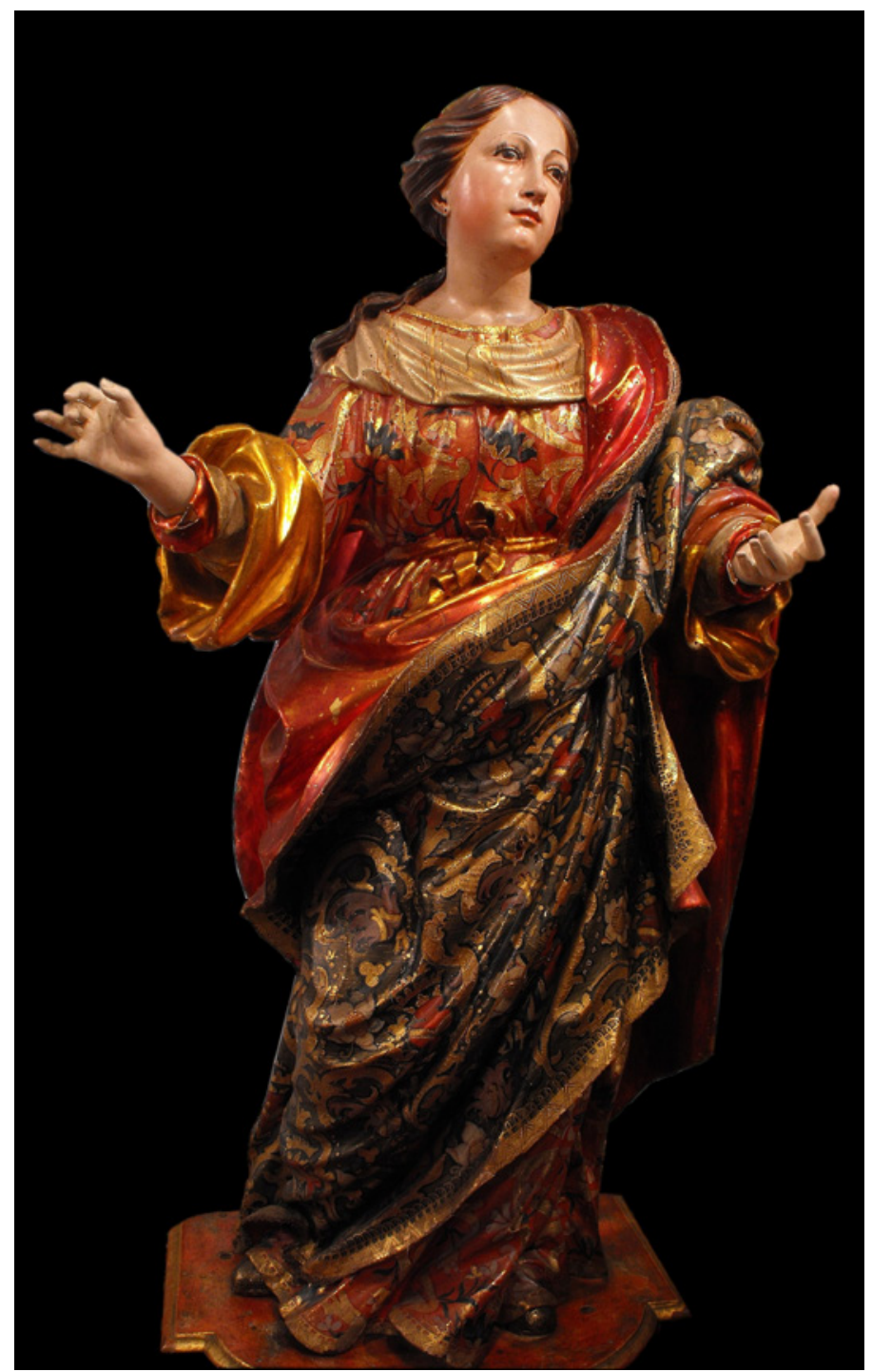

Figura 5. Virgen del coro del convento de Madre de Dios de Sanlúcar de Barrameda. 


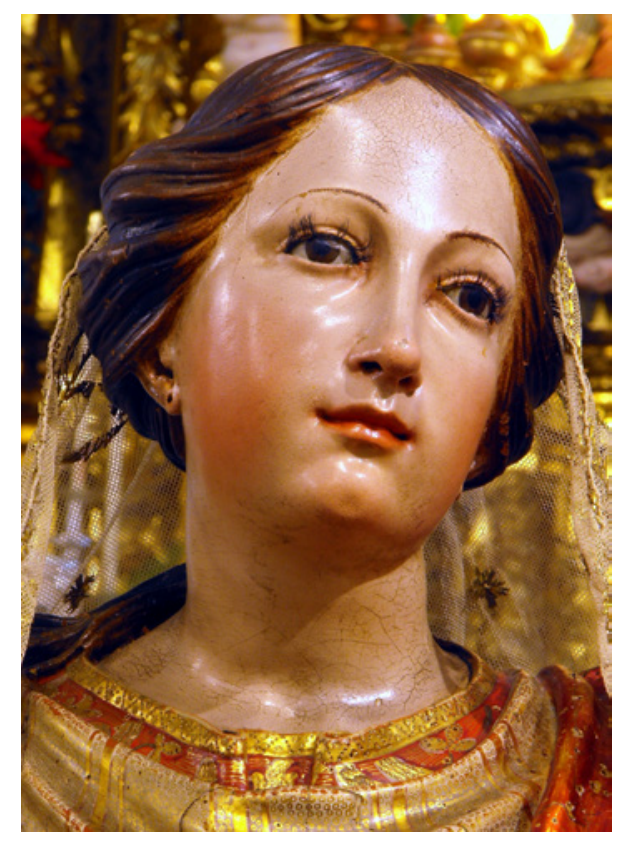

Figura 6. Virgen del coro del convento de Madre de Dios de Sanlúcar de Barrameda. (detalle).

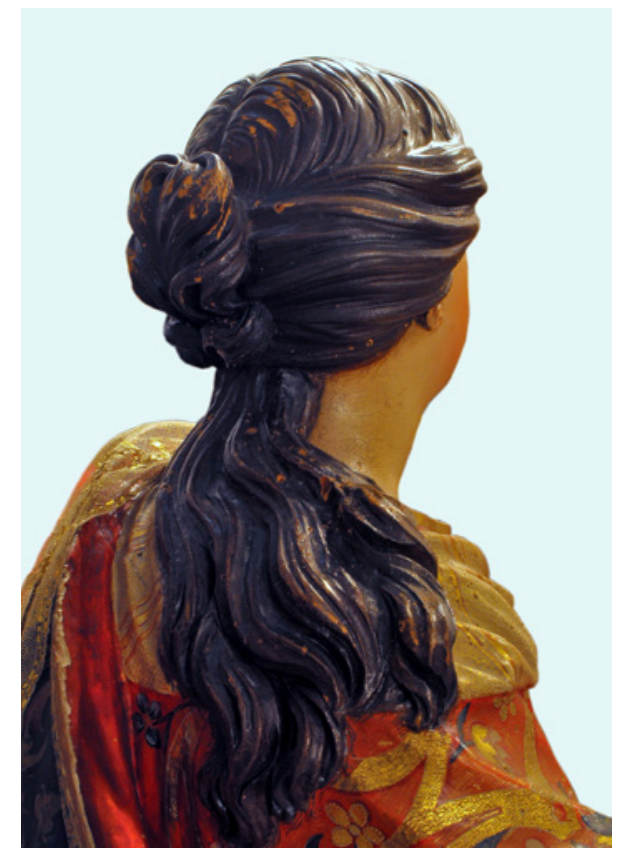

Figura 7. Virgen del coro del convento de Madre de Dios de Sanlúcar de Barrameda. (detalle). 


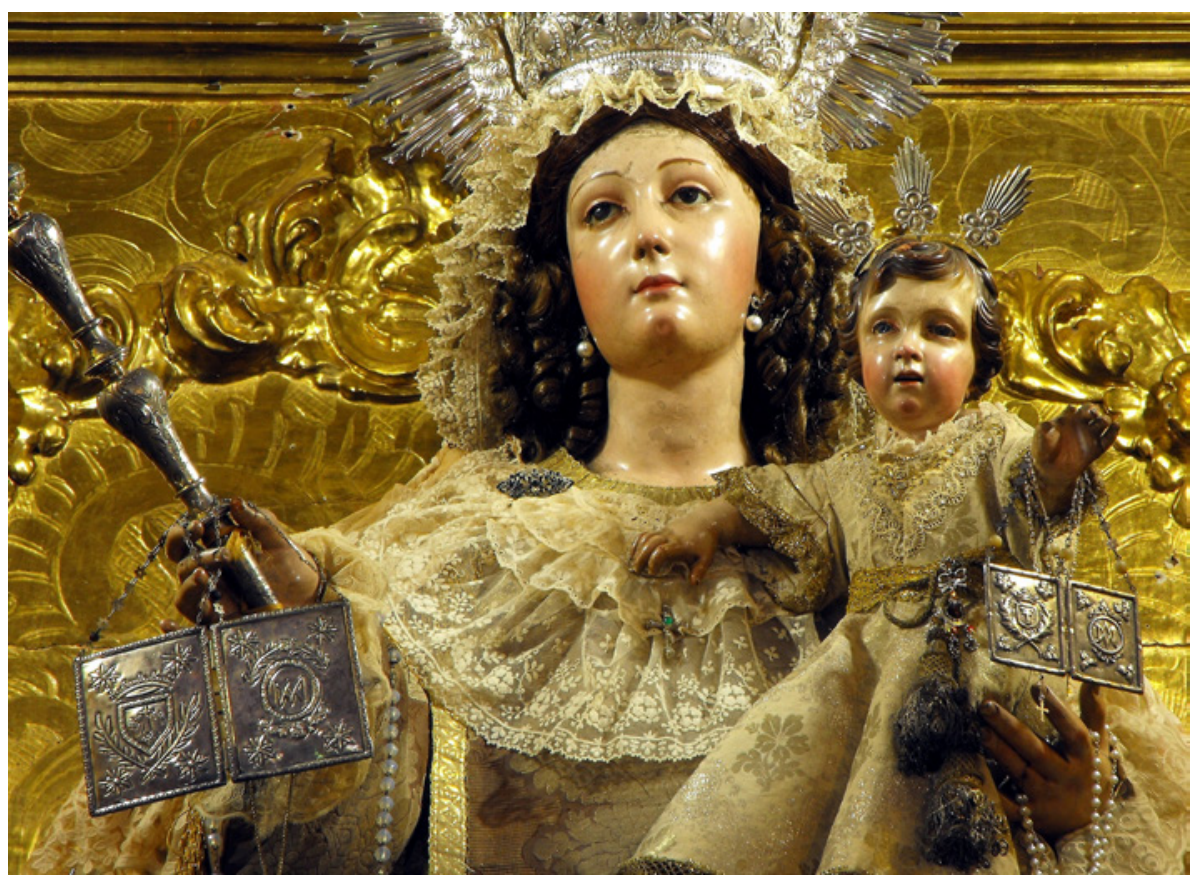

Figura 8. Virgen del Carmen de la parroquia del Carmen de Sanlúcar de Barrameda. 


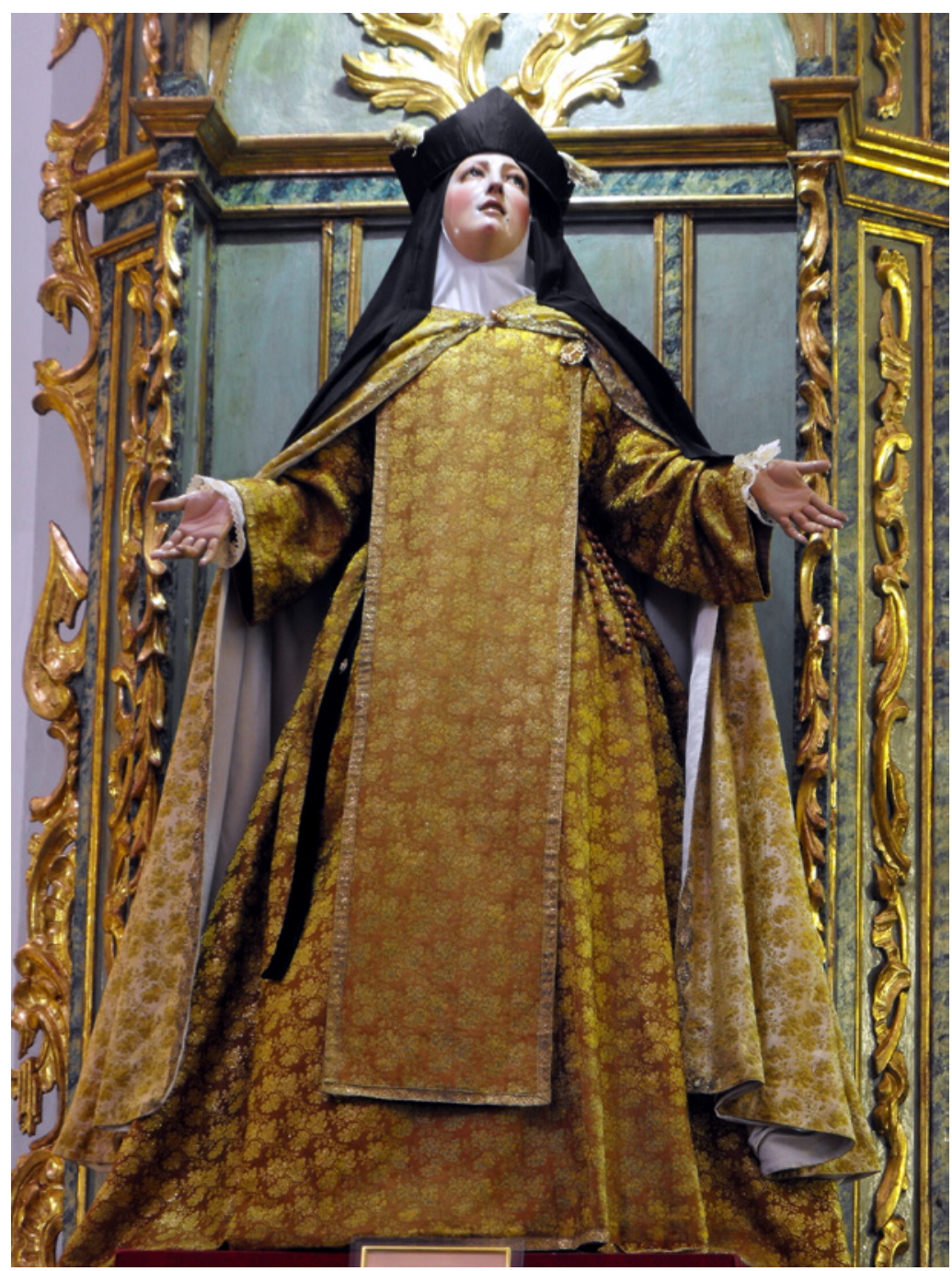

Figura 9. Sata Teresa de Jesús de la parroquia del Carmen de Sanlúcar de Barrameda. 


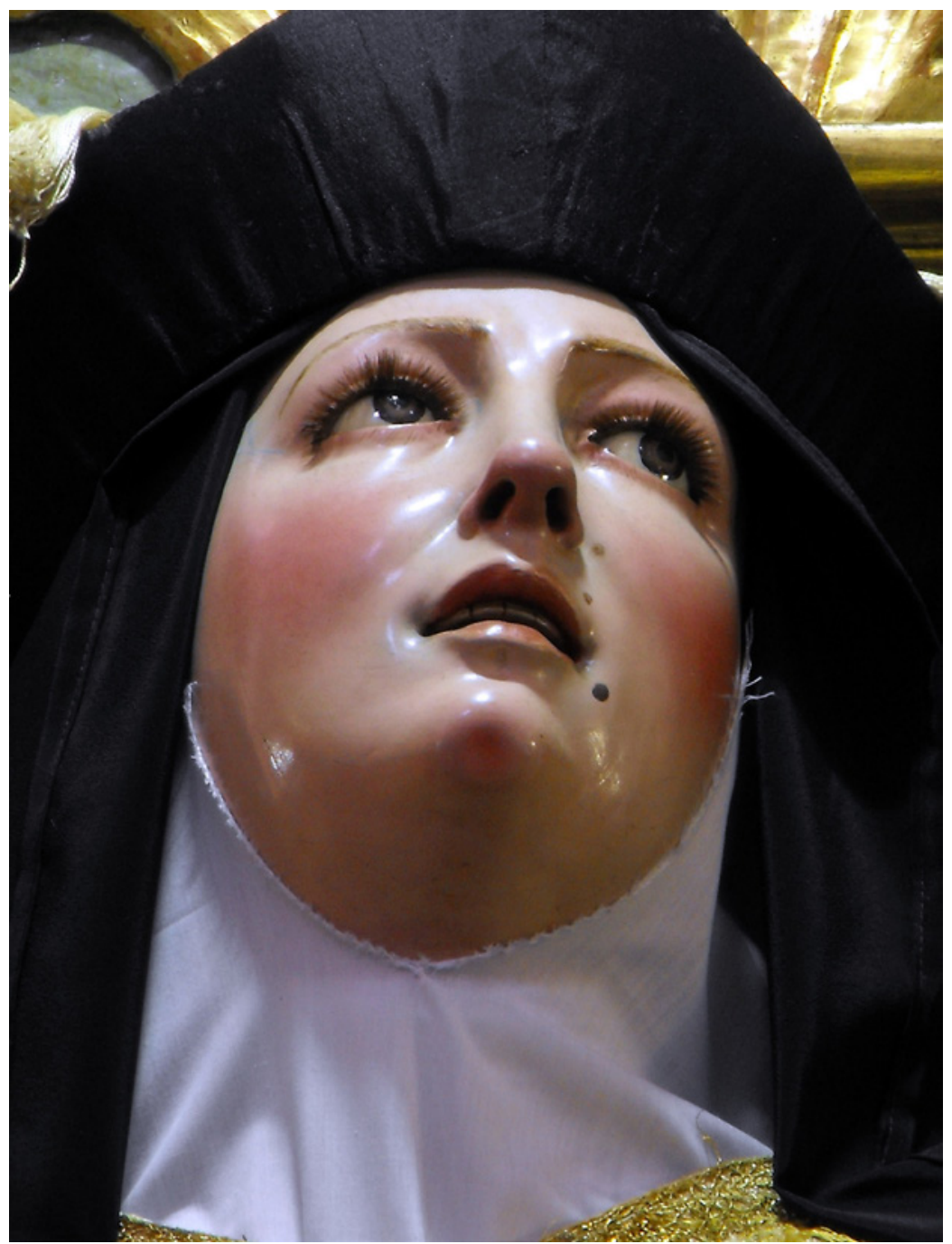

Figura 10. Santa Teresa de Jesús de la parroquia del Carmen de Sanlúcar de Barrameda. (detalle). 